\section{Review \\ Portrait of Candida Species Biofilm Regulatory Network Genes}

\author{
Daniela Araújo, ${ }^{1}$ Mariana Henriques, ${ }^{1}$ and Sónia Silva ${ }^{1, \star}$
}

Most cases of candidiasis have been attributed to Candida albicans, but Candida glabrata, Candida parapsilosis and Candida tropicalis, designated as non-C. albicans Candida (NCAC), have been identified as frequent human pathogens. Moreover, Candida biofilms are an escalating clinical problem associated with significant rates of mortality. Biofilms have distinct developmental phases, including adhesion/colonisation, maturation and dispersal, controlled by complex regulatory networks. This review discusses recent advances regarding Candida species biofilm regulatory network genes, which are key components for candidiasis.

\section{Candida: Both a Commensal and a Pathogen}

Of the fungi regarded as human pathogens, members of the genus Candida are the most frequently recovered from fungal infections and these Candida infections are collectively referred to as candidiasis. The genus Candida is an extremely heterogeneous group of over 150 species, but it is well established that only a few of these are implicated in human infectious diseases [1]. Furthermore, it is clear that fungal infections have emerged as important public health problems and candidiasis has been associated with high morbidity and mortality [1].

Candida species normally exist as commensals, but they are opportunistic pathogens with the ability to cause superficial and systemic infections [2]. The prevalence of opportunistic Candida infections has dramatically increased over recent decades, and this is particularly evident in immunocompromised individuals [3]. Although most of the cases of candidiasis have been attributed to $C$. albicans, in recent decades improved diagnostic methods and higher levels of resistance to certain antifungals [4] have led to the appearance of NCAC species, particularly C. glabrata, C. parapsilosis, and C. tropicalis [5]. Moreover, the pathogenicity of Candida species is facilitated by a number of virulence factors, including dimorphism, secretion of hydrolytic enzymes (such as proteases, lipases, and haemolysins) and the ability to adhere and form biofilm on medical devices and/or the host mucosal epithelium [6].

It is assumed that one of the major contributions to Candida species virulence is its versatility to adapt to a variety of different habitats and the formation of surface-attached microbial communities, known as biofilms [5]. Biofilm development by Candida species is a fascinatingly intricate process involving fine alterations in gene expression, requiring complex and well coordinated regulation to accomplish the process with high efficiency, both spatially and temporally. Thus, this review examines recent advances about the regulators of biofilm network genes in Candida species that are key components of candidiasis.

\section{Trends}

Candida albicans is the main cause of candidiasis, however, non-C. albicans Candida species are now frequently identified as potential human pathogens.

Biofilm formation is a potent virulence factor for a number of Candida species, as it confers significant resistance to traditional antifungal therapy.

There are common genetic requirements for biofilm formation; however, much work is needed to complete the picture of biofilm regulatory network genes.

${ }^{1}$ Centre of Biological Engineering (CEB), University of Minho, Braga, Portugal

${ }^{*}$ Correspondence: soniasilva@deb.uminho.pt (S. Silva). 


\section{Biofilm Formation by Candida Species}

Biofilms are communities of microorganisms properly organized and embedded in an extracellular matrix [7]. This mode of growth is a potent virulence factor for all Candida species. Moreover, C. albicans, C. parapsilosis, C. tropicalis and C. glabrata isolates are good biofilm formers, and the presence of biofilms during infection has been related to higher morbidity and mortality rates compared to isolates incapable of forming biofilms [8].

Biofilm formation is a sequential phenomenon which involves attachment, maturation, and detachment [9], as illustrated in Figure 1. Attachment and colonisation of yeast cells to an abiotic or/and biotic surface is the first step of biofilm development (Figure 1A). Initial attachment of Candida cells is followed by cell division, this proliferation leading to the formation of a basal layer of anchoring microcolonies [9,10] (Figure 1B), and then subsequent biofilm maturation (Figure 1C). The biofilm maturation is, generally, characterized by the presence of filamentous

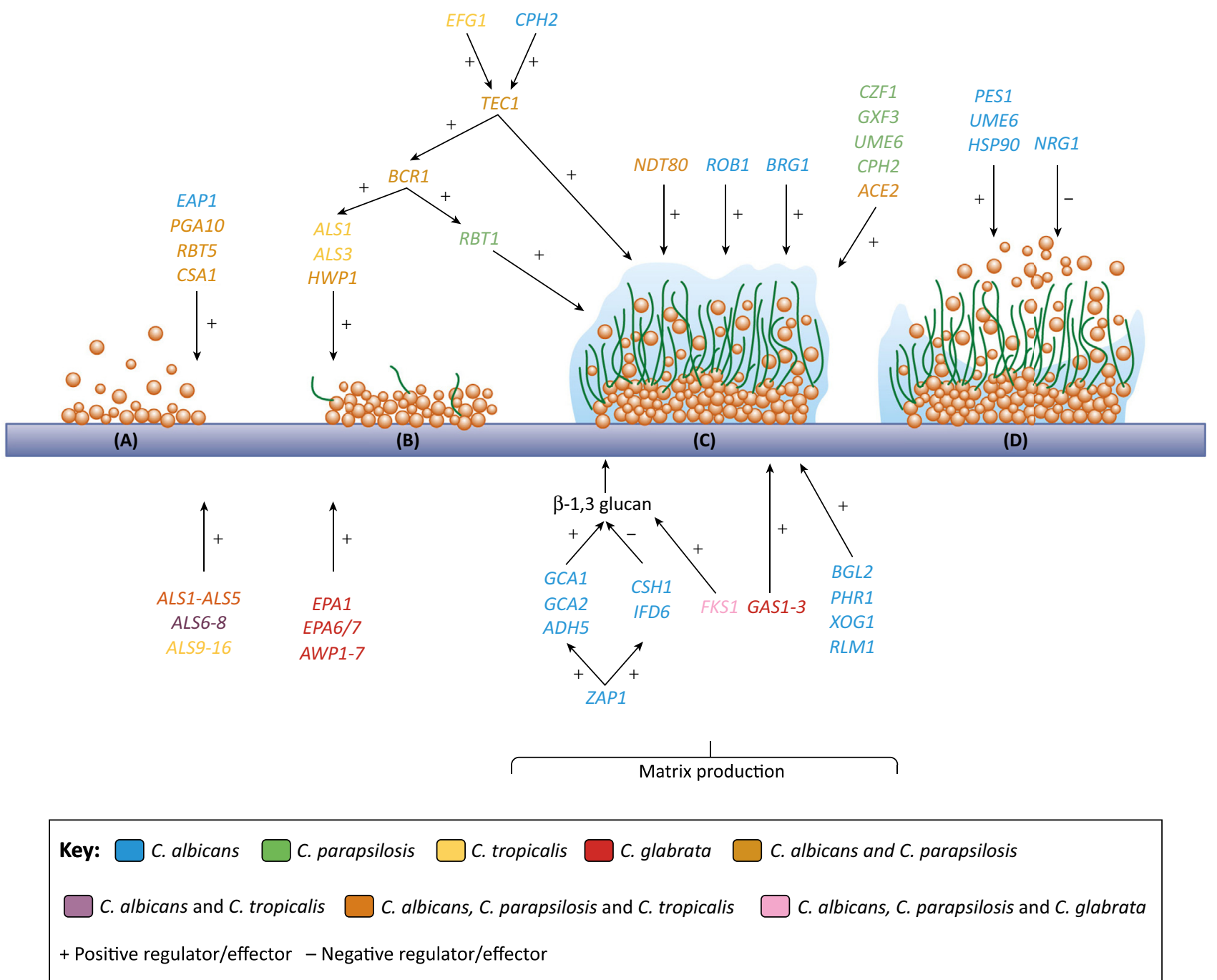

Trends in Microbiology

Figure 1. Regulatory Network Genes for the Different Biofilm Stages of Candida albicans, Candida parapsilosis, Candida tropicalis, and Candida glabrata. (A) Initial adhesion. (B) Formation of basal microcolony layers. (C) Mature biofilm constituted by cells with diverse morphologies and extracellular matrix. (D) Biofilm detachment and dispersion. 

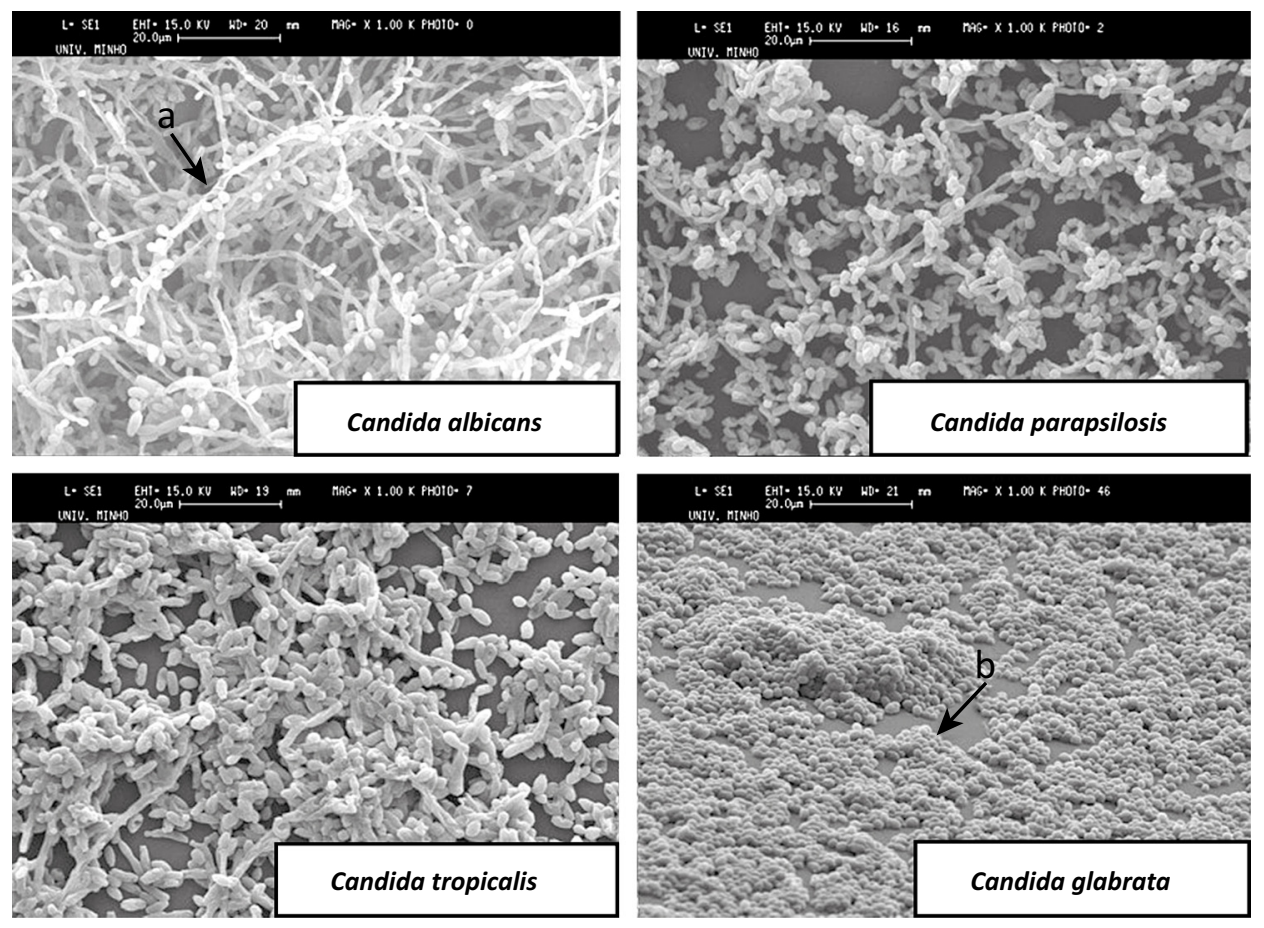

Trends in Microbiology

Figure 2. Biofilm Structure of Candida albicans, Candida parapsilosis, Candida tropicalis, and Candida glabrata. Filamentous forms (hyphae or pseudohyphae). Blastospores. Images obtained with scanning electron microscopy after $24 \mathrm{~h}$ of biofilm growth.

forms, pseudohyphae and/or hyphae, and by the production of extracellular matrix [10,11]. The role of the matrix is to protect Candida cells from phagocytic cells and to act as a barrier to drugs and toxic substances $[12,13]$. Moreover, this matrix allows the maintenance of nutrients within it to reach biofilm cells $[12,13]$. Finally, mature biofilms have the ability to initiate detachment and dispersion (Figure 1D) on their own. Furthermore, this release of cells from the original biofilm community is a step forward in generating novel communities at new locations [14].

It is important to address the fact that biofilms are variable in their structure and matrix composition, differing between species and strains [15] (Figure 2 and Table 1). In the case

Table 1. Biofilm Characteristics of Candida albicans, Candida parapsilosis, Candida tropicalis, and Candida glabrata

\begin{tabular}{|l|l|l|l|}
\hline Species & Biofilm Structure & Matrix Composition & Refs \\
\hline C. albicans & $\begin{array}{l}\text { Bilayer structure with yeast, hyphae, } \\
\text { and pseudohyphae }\end{array}$ & $\begin{array}{l}\text { Mainly composed by carbohydrates, } \\
\text { proteins, phosphorus, and } \\
\text { hexosamines }\end{array}$ & {$[3,11,12,14,73,74]$} \\
\hline C. parapsilosis & $\begin{array}{l}\text { Thin biofilm consisting of aggregated } \\
\text { blastospores with yeast cells and } \\
\text { pseudohyphae }\end{array}$ & $\begin{array}{l}\text { High quantities of carbohydrates and } \\
\text { low levels of proteins }\end{array}$ & {$[4,74-77]$} \\
\hline C. tropicalis & $\begin{array}{l}\text { Dense network of yeast cells with } \\
\text { evident filamentous morphologies }\end{array}$ & $\begin{array}{l}\text { Low levels of carbohydrates and } \\
\text { proteins }\end{array}$ & {$[4,7,11,74]$} \\
\hline C. glabrata & $\begin{array}{l}\text { Compact monolayer or multilayer } \\
\text { of only blastospores }\end{array}$ & $\begin{array}{l}\text { High levels of carbohydrates and } \\
\text { proteins; mainly composed of } \\
\text { hexosamine }\end{array}$ & {$[5,7,11,74]$} \\
\hline
\end{tabular}


of $C$. albicans, the biofilm structure normally consists of two layers, a basal deposit of blastospores covered by a thick matrix film with hyphal forms (Figure 2). Furthermore, biofilm formation in this species is related to the transition from yeast to hyphal growth, as mentioned above [14]. Compared to $C$. albicans, biofilms of $C$. parapsilosis are much less thick, consisting of aggregated blastospores with yeast cells and pseudohyphae [4] (Figure 2). In the case of $C$. tropicalis, mature biofilms are usually characterised by a dense network of yeast cells with evident filamentous morphologies. In contrast to this species (Figure 2), C. glabrata biofilms are characterised by a compact monolayer or multilayer with only blastospores, since this species is unable to form filamentous forms (Figure 2) [5].

Table 1 summarizes the general characteristics of the four most important pathogenic Candida species. Carbohydrates, proteins, phosphorus, and hexosamines are the major constituents of the biofilm matrix of $C$. albicans $[12,16]$. In the case of $C$. parapsilosis, Silva et al. [7] reported that the extracellular matrices contain high quantities of carbohydrates; however, the quantity of protein is lower compared with that of other species. The matrices of $C$. glabrata and C. tropicalis are also composed of proteins and carbohydrates [5], but C. glabrata has higher levels as compared to C. tropicalis [7].

\section{Regulatory Network Genes for the Different Biofilm Phases of Candida Species}

Mucosal infections could be associated with biofilms in that the pathogen adheres to a surface and produces an extracellular matrix [17]. This relationship has prompted investigations to test the hypothesis that genes required for biofilm formation in vitro may be required for mucosal infection as well. Findings from these studies have underscored the utility of this perspective in that there are several common genetic requirements for the formation and development of biofilms on abiotic and mucosal surfaces [9]. The distinct developmental phases of biofilms (adhesion/colonisation, maturation, and dispersal) are directed by complex molecular events. Biofilm formation is strongly dependent on environmental conditions, which makes the comparison of regulatory genetic alterations among Candida species not easy. It should also be noted that the whole genome is only known for $C$. albicans and C. glabrata. Despite that, the currently known regulatory network of genes involved in biofilm formation for $C$. albicans, C. parapsilosis, C. glabrata, and C. tropicalis are described and compared below and summarized in Table 2.

\section{Adherence and/or Colonisation}

Adherence of Candida cells to mucosal surfaces and/or synthetic material is an early step leading to proliferation and consequently biofilm formation and infection (Figure 1) [4]. The adhesion mechanism is based on interaction between the cell wall of the microorganism and cell surfaces of the host. Thereby, adherence is mediated by host cells, fungal cells, and environmental conditions [18]. Modulation of the adhesion process can be achieved by microbial adhesins or host cell receptors, or by physical and chemical manipulations [19].

The presence of specific cell-wall proteins, designated normally as adhesins, is a trigger in the modulation of the adhesion process [5]. In C. albicans, the adhesion is mediated by agglutininlike sequence (Als) proteins (Figure 1) [6]. The family of Als adhesins in C. albicans consists in eight members, namely Als1-7 and 9, and all proteins have a similar structure containing an $\mathrm{N}$-terminal secretory signal sequence [6]. Specifically, Als1 and Als3 proteins are involved in biofilm surface attachment; however, their expression differs depending on C. albicans cell morphology [20]. In the case of ALS1, expression is detectable in both yeast and hyphal cell morphology [21], but ALS3 is expressed only in the hyphal lifestyle [22]. Of the eight ALS genes, ALS1, ALS3, and ALS5 are reported to be involved in the adhesion of $C$. albicans to a variety of biotic substrates [23]. 
Table 2. Genes Involved in Genetic Control of Adherence and Biofilm Formation in Candida albicans, Candida parapsilosis, and Candida glabrata Species

\begin{tabular}{|c|c|c|c|c|c|}
\hline Species & & $\begin{array}{l}\text { Systematic } \\
\text { Name }\end{array}$ & $\begin{array}{l}\text { Gene } \\
\text { Name }\end{array}$ & Description & Refs \\
\hline \multirow[t]{19}{*}{ C. albicans } & \multirow[t]{8}{*}{$\begin{array}{l}\text { Adhesion } \\
\text { and/or } \\
\text { colonisation }\end{array}$} & $\begin{array}{l}\text { Orf19.5741/ } \\
\text { Orf19.1816 }\end{array}$ & $\begin{array}{l}\text { ALS1/ } \\
\text { ALS3 }\end{array}$ & $\begin{array}{l}\text { Cell-wall protein adhesin; } \\
\text { involved in adherence to } \\
\text { vascular endothelial cells and } \\
\text { oral epithelial cells }\end{array}$ & {$[35,78,79]$} \\
\hline & & Orf19.5736 & ALS5 & $\begin{array}{l}\text { Cell-wall protein involved in } \\
\text { adherence process }\end{array}$ & {$[78,79]$} \\
\hline & & Orf19.1321 & HWP1 & $\begin{array}{l}\text { Cell-wall adhesin; involved in } \\
\text { adhesion step: promotes } \\
\text { physical contact between } \\
\text { epithelial cells and the fungal } \\
\text { cells }\end{array}$ & {$[25,27,80]$} \\
\hline & & Orf19.1401 & EAP1 & $\begin{array}{l}\text { GPI-linked cell wall protein; } \\
\text { involved in the cell-cell adhesion }\end{array}$ & $\begin{array}{l}{[10,21} \\
24,73]\end{array}$ \\
\hline & & Orf19.5674 & PGA10 & $\begin{array}{l}\text { GPI membrane protein; involved } \\
\text { in full adherence and essential for } \\
\text { biofilm development }\end{array}$ & {$[10,29,81]$} \\
\hline & & Orf19.6274 & PBR1 & $\begin{array}{l}\text { White cell } \propto \text { factor-induced } \\
\text { gene; full adherence }\end{array}$ & {$[10,28,82]$} \\
\hline & & Orf.19.4477 & $\mathrm{CSH} 1$ & $\begin{array}{l}\text { White cell } \propto \text { factor-induced } \\
\text { gene; full adherence of biofilm }\end{array}$ & {$[10,28,82]$} \\
\hline & & Orf19.3127 & CZF1 & $\begin{array}{l}\text { Transcription factor; required for } \\
\text { yeast adherence to silicone }\end{array}$ & {$[50]$} \\
\hline & \multirow[t]{11}{*}{ Maturation } & Orf19.1321 & HWP1 & $\begin{array}{l}\text { Hyphal cell-wall mannoprotein; } \\
\text { required for hyphal formation }\end{array}$ & $\begin{array}{l}{[23,25,27,} \\
80,83,84]\end{array}$ \\
\hline & & Orf19.723 & $B C R 1$ & $\begin{array}{l}\text { Transcription factor required for } \\
\text { biofilm formation; involved in the } \\
\text { early adhesion stage }\end{array}$ & $\begin{array}{l}{[17,38} \\
73,76]\end{array}$ \\
\hline & & Orf19.610 & EFG1 & $\begin{array}{l}\text { Transcription factor of biofilm } \\
\text { formation; Involved in cell } \\
\text { surface, adhesion and hyphal } \\
\text { formation }\end{array}$ & $\begin{array}{l}{[9,38,43} \\
85-87]\end{array}$ \\
\hline & & Orf19.5908 & TEC1 & $\begin{array}{l}\text { Transcription factor required for } \\
\text { biofilm formation; required for } \\
\text { hyphal formation }\end{array}$ & $\begin{array}{l}{[38,40,44,} \\
46,73,82]\end{array}$ \\
\hline & & Orf19.2119 & NDT80 & $\begin{array}{l}\text { Transcription factor of biofilm } \\
\text { formation; involved in hyphal } \\
\text { development }\end{array}$ & {$[9,40]$} \\
\hline & & Orf19.4998 & $R O B 1$ & $\begin{array}{l}\text { Transcription factor of biofilm } \\
\text { formation }\end{array}$ & {$[6,9]$} \\
\hline & & Orf19.4056 & BRG1 & $\begin{array}{l}\text { Transcription factor of biofilm } \\
\text { formation }\end{array}$ & {$[6,9]$} \\
\hline & & Orf19.1822 & UME6 & $\begin{array}{l}\text { Transcription regulator of yeast- } \\
\text { filament transition }\end{array}$ & {$[40,72,88]$} \\
\hline & & Orf19.1187 & $\mathrm{CPH} 2$ & $\begin{array}{l}\text { Transcription factor; promotes } \\
\text { hyphal growth }\end{array}$ & {$[51]$} \\
\hline & & Orf19.6124 & ACE2 & $\begin{array}{l}\text { Involved in regulation of biofilm } \\
\text { development }\end{array}$ & [48] \\
\hline & & Orf19.3794 & ZAP1 & $\begin{array}{l}\text { Negative regulator of biofilm } \\
\text { matrix production; high levels of } \\
\beta-1,3 \text { glucan both in vitro as in } \\
\text { vivo in } \Delta \text { zap1/zap1 }\end{array}$ & $\begin{array}{l}{[6,10} \\
56,89]\end{array}$ \\
\hline
\end{tabular}


Table 2. (continued)

\begin{tabular}{|c|c|c|c|c|c|}
\hline Species & & $\begin{array}{l}\text { Systematic } \\
\text { Name }\end{array}$ & $\begin{array}{l}\text { Gene } \\
\text { Name }\end{array}$ & Description & Refs \\
\hline & & Orf19.5101 & CCR4 & $\begin{array}{l}\text { Negative regulator of biofilm } \\
\text { matrix production; over- } \\
\text { production of extracellular matrix } \\
\text { in } \Delta c c r 4 / c c r 4\end{array}$ & [61] \\
\hline & & Orf.19.2929 & FKS1 & $\begin{array}{l}\beta-1,3 \text { glucan synthase; biofilm } \\
\text { resistance to fluconazole via a } \\
\text { role in } \beta-1,3 \text { glucan levels in the } \\
\text { extracellular matrix }\end{array}$ & $\begin{array}{l}{[10,54} \\
55,57]\end{array}$ \\
\hline & & Orf.19.4477 & $\mathrm{CSH} 1$ & $\begin{array}{l}\text { Cell-matrix adhesion; negative } \\
\text { regulator of matrix production } \\
\text { when } Z A P 1 \text { is activated }\end{array}$ & {$[10,56]$} \\
\hline & & Orf.19.1048 & IFD6 & $\begin{array}{l}\text { Negative regulator of matrix } \\
\text { production when } Z A P 1 \text { is } \\
\text { activated }\end{array}$ & {$[10,56]$} \\
\hline & & Orf.19.4899 & GCA1 & $\begin{array}{l}\text { Positive regulator of matrix } \\
\text { production when } Z A P 1 \text { is } \\
\text { activated }\end{array}$ & {$[10,56]$} \\
\hline & & Orf.19.999 & GCA2 & $\begin{array}{l}\text { Positive regulator of matrix } \\
\text { production when } Z A P 1 \text { is } \\
\text { activated }\end{array}$ & {$[10,56]$} \\
\hline & & Orf.19.2608 & $A D H 5$ & $\begin{array}{l}\text { Positive regulator of matrix } \\
\text { production when } Z A P 1 \text { is } \\
\text { activated }\end{array}$ & {$[10,56]$} \\
\hline & & Orf.19.4662 & RLM1 & $\begin{array}{l}\text { Putative transcription factor; } \\
\text { positive regulator of matrix } \\
\text { production }\end{array}$ & {$[57,89]$} \\
\hline & & Orf.19.4565 & $B G L 2$ & $\begin{array}{l}\text { Cell wall 1,3-beta- } \\
\text { glucanosyltransferase; involved } \\
\text { in matrix delivery }\end{array}$ & {$[6,55,60]$} \\
\hline & & Orf.19.3829 & PHR1 & $\begin{array}{l}\text { Glucanosyltransferase; involved } \\
\text { in matrix delivery }\end{array}$ & {$[55,59]$} \\
\hline & & Orf.19.2990 & XOG1 & $\begin{array}{l}\beta-1,3 \text { exoglucanase involved in } \\
\text { matrix delivery }\end{array}$ & {$[6,55,58]$} \\
\hline & Dispersion & Orf19.7150 & NRG1 & $\begin{array}{l}\text { Transcription factor; } \\
\text { overexpression increases } \\
\text { released cells; negative regulator } \\
\text { of filamentation }\end{array}$ & $\begin{array}{l}{[10,44} \\
69-72,88]\end{array}$ \\
\hline & & Orf19.4093 & PES1 & $\begin{array}{l}\text { Responsible for reverse } \\
\text { morphological transition (from } \\
\text { hyphae to yeast): } \\
\text { overexpression increases } \\
\text { released cells }\end{array}$ & $\begin{array}{l}{[10,67} \\
69,90]\end{array}$ \\
\hline & & Orf19.1822 & UME6 & $\begin{array}{l}\text { Transcription regulator of yeast- } \\
\text { filament transition; } \\
\text { overexpression reduces } \\
\text { released cells }\end{array}$ & $\begin{array}{l}{[67,72,88,} \\
90,91]\end{array}$ \\
\hline & & Orf19.6515 & HSP9O & $\begin{array}{l}\text { Biofilm azole resistance; key } \\
\text { regulator in biofilm dispersal }\end{array}$ & $\begin{array}{l}{[6,67} \\
89,92]\end{array}$ \\
\hline C. parapsilosis & Attachment & CPAR2_403520 & HWP1 & $\begin{array}{l}\text { Cell adhesion; involved in } \\
\text { attachment step and } \\
\text { consequently in biofilm formation }\end{array}$ & [25] \\
\hline & & & ALS1-5 & $\begin{array}{l}\text { Putative adhesins involved in } \\
\text { adhesion step }\end{array}$ & [31] \\
\hline
\end{tabular}


Table 2. (continued)

\begin{tabular}{|c|c|c|c|c|c|}
\hline Species & & $\begin{array}{l}\text { Systematic } \\
\text { Name }\end{array}$ & $\begin{array}{l}\text { Gene } \\
\text { Name }\end{array}$ & Description & Refs \\
\hline & \multirow[t]{10}{*}{ Maturation } & CPAR2_205990 & $B C R 1$ & $\begin{array}{l}\text { Transcription factor required for } \\
\text { biofilm formation; when the } \\
\text { ortholog is deleted, the biofilm } \\
\text { formed is thinner }\end{array}$ & $\begin{array}{l}{[38,40,41} \\
73,76,93]\end{array}$ \\
\hline & & CPAR2_701620 & EFG1 & $\begin{array}{l}\text { Transcription factor involved in } \\
\text { biofilm formation and hyphal } \\
\text { growth }\end{array}$ & {$[40,43]$} \\
\hline & & CPAR2_213640 & NDT80 & $\begin{array}{l}\text { Transcription factor activity } \\
\text { involved in biofilm formation }\end{array}$ & {$[40,43]$} \\
\hline & & CPAR2_403510 & $R B T 1$ & $\begin{array}{l}\text { Required for biofilm } \\
\text { development; regulated by } \\
\text { BCR1 }\end{array}$ & {$[76,94]$} \\
\hline & & CPAR2_501290 & CZF1 & $\begin{array}{l}\text { Transcription factor of biofilm } \\
\text { formation }\end{array}$ & [40] \\
\hline & & CPAR2_800210 & GZF3 & $\begin{array}{l}\text { Transcription factor of biofilm } \\
\text { formation }\end{array}$ & [40] \\
\hline & & CPAR2_803820 & UME6 & $\begin{array}{l}\text { Transcription factor of biofilm } \\
\text { formation }\end{array}$ & [40] \\
\hline & & CPAR2_603440 & $\mathrm{CPH} 2$ & $\begin{array}{l}\text { Transcription factor of biofilm } \\
\text { formation }\end{array}$ & [40] \\
\hline & & CPAR2_204370 & ACE2 & $\begin{array}{l}\text { Transcription factor of biofilm } \\
\text { formation }\end{array}$ & [40] \\
\hline & & CPAR2_106400 & FKS1 & $\begin{array}{l}\text { Maturation of biofilm in presence } \\
\text { of glucose }\end{array}$ & [62] \\
\hline \multirow[t]{2}{*}{ C. tropicalis } & Attachment & & $A L S 1-16$ & $\begin{array}{l}\text { Putative adhesins involved in } \\
\text { adhesion step of biofilm } \\
\text { formation }\end{array}$ & [31] \\
\hline & Maturation & & EFG1 & $\begin{array}{l}\text { Filamentation, biofilm formation } \\
\text { and white-opaque switching }\end{array}$ & [45] \\
\hline \multirow[t]{9}{*}{ C. glabrata } & \multirow[t]{7}{*}{ Attachment } & CAGL0E06644g & EPA1 & $\begin{array}{l}\text { Cell adhesion molecule; epithelial } \\
\text { adhesin involved in adherence to } \\
\text { host surface }\end{array}$ & $\begin{array}{l}{[5,23} \\
32-34]\end{array}$ \\
\hline & & $\begin{array}{l}\text { CAGLOC00110g/ } \\
\text { CAGLOC05643g }\end{array}$ & $\begin{array}{l}\text { EPA6/ } \\
\text { EPA7 }\end{array}$ & $\begin{array}{l}\text { Epithelial adhesin involved in } \\
\text { adherence to host surface }\end{array}$ & {$[32,35,95]$} \\
\hline & & $\begin{array}{l}\text { CAGLOJ02508g/ } \\
\text { CAGLOK00110g }\end{array}$ & $\begin{array}{l}\text { AWP1/ } \\
\text { AWP2 }\end{array}$ & Adhesin-like wall protein & {$[36,37,96]$} \\
\hline & & CAGL0J11891g & AWP3 & Putative adhesin-like wall protein & {$[36,37,96]$} \\
\hline & & CAGLOJ11990g & AWP4 & Adhesin-like wall protein & {$[36,37,96]$} \\
\hline & & $\begin{array}{l}\text { CAGLOK13024g/ } \\
\text { CAGLOG10175g }\end{array}$ & $\begin{array}{l}\text { AWP5/ } \\
\text { AWP6 }\end{array}$ & Adhesin-like wall protein & {$[37,96]$} \\
\hline & & CAGL0C00209g & AWP7 & Putative adhesin-like wall protein & [37] \\
\hline & \multirow[t]{2}{*}{ Maturation } & CAGL0G01034g & FKS1 & $\begin{array}{l}\beta-1,3 \text { glucan synthase involved } \\
\text { in cell wall and extracellular } \\
\text { matrix }\end{array}$ & {$[55,63,64]$} \\
\hline & & $\begin{array}{l}\text { CAGLOG00286g/ } \\
\text { CAGLOM13849g/ } \\
\text { CAGLOF01287g }\end{array}$ & $\begin{array}{l}\text { GAS1/ } \\
\text { GAS2/ } \\
\text { GAS5 }\end{array}$ & $\beta-1,3$ glucan synthase & {$[36,65,66]$} \\
\hline
\end{tabular}


Eap1 is a GPI-linked (glycosylphosphatidylinositol-dependent) cell-wall protein which is involved in cell-cell adhesion in C. albicans (Figure 1) [24]. This protein mediates surface binding; its synthesis is regulated by the transcription factor EFG1 [21].

Hyphal wall protein I (Hwp1) is a fungal cell-wall mannoprotein that promotes attachment of Candida cells to the host surface [23]; it was also the first cell-surface protein described as involved in in vivo C. albicans biofilm formation (Figure 1) [25]. In the other instances, Orsi et al. [26] demonstrated that this gene is involved in the formation of germ tubes and hyphal forms and thus promotes physical contact between epithelial cells and the fungi, concluding that Hwp1 is an important effector of $C$. albicans pathogenicity [27]. This gene was extensively studied in C. albicans; however, in the case of NCAC species little is known [25]. Despite that, Wan Harun et al. [25] demonstrated that HWP1 mRNA was also expressed in C. parapsilosis and C. tropicalis, but not detected in C. glabrata. The fact that HWP1 is positively expressed in these three species during the process of adhesion and biofilm formation indicates its involvement in producing adhesins covalently linked to the cell-wall glucan [25].

The cell-surface protein Pga10 and the secreted Pbr1 protein are also described as important for the full adherence of $C$. albicans biofilms (Figure 1) [28]. Pga10, also known as RBT51, is a member of CFEM (common in several fungal extracellular membranes) proteins and has a role in adhesion in C. albicans [29]. Pérez et al. [29] demonstrated that $\Delta$ pga10 forms a less consistent biofilm and contributes to early detachment from the plastic substrate, when compared to the parental strain. Additionally, Sahni et al. [28] showed that C. albicans adhesion to blood cells was lower when the PBR1 gene was deleted.

In C. parapsilosis, adhesion to epithelial and acrylic surfaces was associated with cell-surface hydrophobicity. Moreover, C. parapsilosis has a greater ability than C. albicans to adhere to buccal epithelial cells [30]. Butler et al. [31] identified five members of Als and six members of Pga30 cell-wall proteins, though there has been no further work to understand the role of these proteins in the process of adhesion in C. parapsilosis (Figure 1) [4,31]. In the case of C. tropicalis, Butler et al. [31] identified 16 members of the ALS family in the genome; however, additional confirmative research is needed on their involvement in biofilm development.

Similar to C. albicans, adherence of C. glabrata is mediated by epithelial adhesins (Epa) that have a similar structure to the Als proteins [5]. The family of EPA genes are composed of 17-23 genes, depending on the strain; however, EPA1, EPA6, and EPA7 are the most important adhesins (Figure 1) [32]. Deletion of the EPA1 gene reduces adherence in vitro to host epithelial cells [33], and adherence of this adhesin is inhibited in the presence of lactose [34]. Regarding the Epa6 adhesin, C. glabrata does not normally express EPA6 in vitro; however, it is expressed during urinary infection due to low levels of nicotinic acid [35]. De Groot et al. [36] identified another family of adhesins involved in the first stage of $C$. glabrata biofilm development, namely Awp adhesins (Figure 1). Initially, four Awp adhesins (Awp1-4) were identified using liquid chromatography tandem mass spectrometry [36]. A subsequent study revealed the gene expression profile of the seven Awp adhesins (Awp1-7) [37]. Expression of these adhesins is significantly higher in biofilms when compared to planktonic cells in two different media [37].

Likewise, for C. albicans, NCAC species adhesion mechanisms indicate that the cell wall likely plays a crucial role for colonisation and subsequent biofilm formation.

Biofilm Maturation

Initial attachment of Candida cells is followed by cell division and proliferation, known as biofilm development (Figure 1). The biofilm formation in Candida species is regulated by several transcription factors that play a fundamental role in various pathways, and they have an 
important potential in the regulation of other genes involved in biofilm formation (Table 2) [38]. Nobile et al. [9] investigated the transcriptional network and identified a set of six transcription factors in $C$. albicans that play an important role in the regulation of biofilm formation, namely BCR1, EFG1, TEC1, NDT80, ROB1, and BRG1 (Figure 1) [9]. Furthermore, C. albicans biofilms are defective when any of these regulators are deleted [9]. However, in the case of NCAC species little is known about the influence of these genes in biofilm formation.

$B C R 1$ is a $\mathrm{C}_{2} \mathrm{H}_{2}$ zinc-finger protein essential for biofilm formation in C. albicans and in $\mathrm{C}$. parapsilosis. Moreover, this gene is essential for the expression of several cell-wall proteins in $C$. albicans [38], namely Als1, Als3, and Hwp1 [23,39]. Nobile et al. [38] described that the expression of $A L S 3$ and HWP1 is reduced in a $\triangle b c r 1 / b c r 1$ strain, which was decreased after adherence to plastic, endothelial and epithelial cells $[35,38]$. Another study by Nobile et al. [20] highlighted the complementary surface function between Hwp1 and Als $1 / 3$ adhesins for in vitro and in vivo biofilm formation. Moreover, Nobile et al. [39] also demonstrated that BCR1 is a regulator of adherence but it is not involved in hyphal formation. In C. parapsilosis, the ortholog of $B C R 1$ is also required for biofilm formation [40], and when this gene is deleted, the biofilm formed by $C$. parapsilosis is thinner with scant layer cells compared to a biofilm formed in normal conditions, showing that $B C R 1$ is also required for in vivo biofilm formation (Figure 1) [41]. The CFEM family of proteins are targets of $B C R 1$ in both species and can act as cell-surface receptors or as adhesins [42]. However, the CFEM family has just been described in C. albicans as having a role in biofilm development [41], namely RBT5, PGA10, and CSA1 (Figure 1) [29]. In $C$. parapsilosis, this family consists of seven members, which include the three members of $C$. albicans involved in biofilm formation [41]. In contrast to C. albicans and C. parapsilosis, in C. glabrata the function of $B C R 1$ is unknown at the moment.

EFG1 is another transcription factor required for biofilm formation that regulates the cell surface and hyphal formation [43]. Holland et al. [40] demonstrated similar reduction in biofilm for $C$. albicans and C. parapsilosis when EFG1 is eliminated (Figure 1). This study confirmed the results obtained by Nobile et al. [9] for EFG1 in C. albicans. Connolly et al. [43] also verified that deleting EFG1 reduces biofilm formation in C. parapsilosis. Moreover, $\Delta$ efg1/efg1 strains were unable to form hyphae in C. albicans, even when grown under hypha-inducing conditions [44]. Recently, Mancera et al. [45] identified the C. tropicalis EFG1 gene and confirmed that this transcriptional factor possessed a similar role in C. albicans (Figure 1). This gene is involved in the regulation of filamentation and biofilm formation, since deletion of both alleles is critical for these factors [45]. Furthermore, an ortholog of EFG1 was identified in the genome of $C$. tropicalis; however, its position is completely different to that of EFG1 in C. albicans [45]. Again in the case of $C$. glabrata, the role of this gene is unknown. It is likely that $C$. glabrata does not possess a gene with a similar function in its genome since they are not polymorphic microorganisms.

TEC1 is a gene required for hyphal formation and virulence in C. albicans [39] and is a member of the TEAATTS transcription factor family [46]. The DNA-binding region is contained in 66-76 conserved amino acids in the $\mathrm{N}$-terminus [47]. This gene is regulated by EFG1 [2], which is involved in regulation of filamentous growth. In C. parapsilosis, TEC1, seems not to play the same role as in C. albicans [39], once Holland et al. [40] did not observe a dramatic reduction in biofilm formation in the case of $C$. parapsilosis mutant for this gene (Figure 1). It is unclear whether TEC1 is involved in C. glabrata biofilm formation.

Other transcription factors described by Nobile et al. [9] in C. albicans biofilm development, NDT80, BRG1, and ROB1, were studied also by Holland et al. [40] in C. parapsilosis (Figure 1). NDT80 is a key factor in response to different environmental conditions and is involved in hyphal development and virulence in C. albicans [40]. In C. parapsilosis, NDT80 deletion results in a 
significant growth defect in biofilm formation. Furthermore, deleting BRG1 does not dramatically reduce biofilms in $C$. parapsilosis [40], indicating that this gene is not involved in biofilm formation in this species. In C. parapsilosis there is no ortholog of the ROB1 gene [40].

Biofilm development in C. parapsilosis is regulated by further transcription factors, namely CZF1, GZF3, UME6, CPH2, and ACE2 (Figure 1) [40]. Biofilm formation is dramatically reduced when ACE2 is deleted [40]. However, this gene is also involved in regulation of biofilm development in C. albicans, controlling the adherence of this species and cell division (namely, M and early G1 phases of the cell cycle) [48]. However, when ACE2 was inactivated in C. glabrata, its ability to cause disease increased significantly [49]. Wätchler et al. [50] described CZF1 as a gene that contributes to yeast adhesion in $C$. albicans, leading to invasion and damage in the oral cavity. The GZF3 gene is a GATA-type transcription factor [40]; however, according to Nobile et al. [9] it is not a key gene in biofilm development in $\mathrm{C}$. albicans. In this species, $\mathrm{CPH} 2$ promotes hyphal growth [51] and regulates the expression of TEC1, which is a transcription factor of biofilm formation as described above [52].

The production of extracellular matrix is another important feature in biofilm maturation [10]. As described above, the composition of the matrix varies according to species, strains, and environmental conditions, and it is well known that the main components of the matrix are carbohydrates and proteins [11]. One of the carbohydrates present in C. albicans matrix is $\beta-1,3$ glucan [53]. However, a recent study by Zarnowski et al. [16] demonstrated that $\beta-1,6$ glucan is also an important matrix component, and that it is highly dependent on the environmental conditions used. The gene responsible for glucan synthase is FKS1 (Figure 1), more commonly designated GSC1, and it has been implicated in C. albicans biofilm resistance to fluconazole [53]. The susceptibility to fluconazole is the result of FKS1 disruption which reduces the deposition of $\beta-1,3$ glucan in the biofilm matrix [54]. Furthermore, the increase in FKS1 transcription is coupled with a reduction in the delivery of glucan to matrix [55]. In C. albicans, $R L M 1$ and $Z A P 1$ are two other regulators involved in matrix production in biofilms (Figure 1). The transcription factor $Z A P 1$ is a negative regulator of biofilm matrix production, and $\triangle$ zap1/zap1 produces a biofilm with high levels of $\beta-1,3$ glucan both in vitro as in vivo [56]. Some target genes of $Z A P 1$ are $C S H 1$, IFD6, GCA1, GCA2, and $A D H 5$, which modulate levels of $\beta-1,3$ glucan in the biofilm matrix (Figure 1) [56]. In the case of CSH1 and IFD6, when ZAP1 activates the expression of these genes, the production of $\beta-1,3$ glucan decreases and therefore these genes are considered as negative regulators of matrix production [56]. However, GCA1, GCA2, and $A D H 5$ are positive regulators since there is an increase in $\beta-1,3$ glucan when these genes are activated by the ZAP1 gene [56]. Another regulator of matrix production is $R L M 1$, a positive regulator, whose deletion promoted a reduction in its matrix levels [57]. Taff et al. [55] described a role for BGL2, PHR1, and XOG1 (Figure 1) as glucan-modifying genes involved in glucan delivery and matrix incorporation. The BGL2 and PHR1 genes encode glucanosyltransferases, and $X O G 1$ is a $\beta-1,3$ exoglucanase [58-60]. Recently, Verma-Gaur et al. [61] identified another gene regulator of biofilm matrix production in C. albicans, CCR4. The authors [61] identified in $\Delta c c r 41 /$ ccr4 C. albicans biofilms several structural modifications with morphological changes and overproduction of extracellular matrix. Therefore, as in the case of ZAP1, the CCR4 gene is another negative regulator [61].

In addition, in C. parapsilosis, the gene FKS1 is involved in maturation of biofilms in the presence of glucose (Figure 1) [55]. Pereira et al. [62] demonstrated that the upregulation of FKS1 is induced by high levels of glucose, leading to an increase in $\beta-1,3$ glucan synthesis. This glucan is accumulated in the matrix, forming a dense and structured biofilm [62]. Little is known about the composition of the biofilm matrix of $C$. glabrata; however, it is known that it is composed of $\beta-1,3$ glucan [4]. As in the previous species, the FKS1 gene is responsible for production of $\beta-1,3$ glucan in C. glabrata (Figure 1) [55], and echinocandins inhibit $\beta-1,3$ glucan synthase by 
targeting FKS subunits $[63,64]$. The GAS gene family is another regulator in the production of $\beta$ 1,3 glucan in this species [36]. Similarly to Saccharomyces cerevisiae, GAS1, GAS2, and GAS5 are a glycosylphosphatidylinositol (GPI)-anchored cell-surface proteins [65] which are involved in the production of $\beta-1,3$ glucan in C. glabrata (Figure 1) [66].

\section{Biofilm Detachment and Dispersion}

The last step is characterized by dispersal of yeast cells and/or pieces of the biofilm from its mature form; this allows the organism to colonize new sites for further adherence and colonization [9], completing the biofilm life cycle (Figure 1). Biofilm dispersion occurs in response to environmental changes, such as a decrease in, or lack of, nutrients or other modifications in the growth media composition [67]. Furthermore, the dispersion of biofilm cells can lead to a development of infections in deep organs due to the ability to invade the bloodstream [67]. In the past decade, early events associated with Candida biofilm formation have received considerable attention. However, very little is known about Candida biofilm dispersion or the mechanisms and genes that trigger it.

Recent studies on C. albicans biofilms have reported that the majority of dispersed cells are yeast cells and that there are three regulatory genes in this step, namely, PES1, UME6, and NRG1 (Figure 1) [10]. Uppuluri et al. [67] demonstrated that the major yeast cells dispersed from biofilm were released from the upper hyphal layers. Furthermore, overexpression of $P E S 1$ results in an increase of yeast growth when cells were grown on medium without doxycycline (DOX) [68]. By contrast, when NRG1 was overexpressed, in the absence of DOX, the biofilm contained only a monolayer of yeast and pseudohyphae cells [69] since NRG1 is a negative regulator of filamentation [70,71]. UME6 is a transcription regulator of yeast-filament transition in C. albicans, and more precisely it is required for hyphal extension (Figure 1) [72]. When UME6 was deleted, there was a little reduction in the C. albicans biofilm [40], which means that this gene has a minor role in biofilm development.

Summarizing, despite all Candida species having some similar regulatory genes in each stage of biofilm formation, there is a lack of information concerning NCAC species, which makes a comparison among them difficult. However, it is possible to stress that the ALS genes are involved in the adhesion process of the three Candida species (C. albicans, C. parapsilosis, and C. tropicalis), and that in C. glabrata this phenomenon is regulated by the Epas, which have a similar structure to the Als proteins. Additionally, some transcription factors described as involved in C. albicans biofilm formation (BCR1, EFG1, and HWP1) are the same as those implicated in C. parapsilosis biofilms. C. glabrata is the species that presents more contrasts in relation to the other Candida species, reflecting its genetic distance.

However, despite all our knowledge about $C$. albicans biofilm regulators, little is known about their involvement in other NCAC species, and thus much more research must be conducted in order to increase our knowledge in this area.

\section{Concluding Remarks}

Biofilms are communities of microorganisms embedded in an extracellular matrix, and biofilms are assumed to be the most important virulence factors for pathogenicity in Candida species. These species utilize several genes that are confirmed to play an important role in the different stages of biofilm development. Indeed, additional and comparative genomic (genome sequencing) and transcriptomic approaches (RNA seq and/or microarrays) are needed to deepen our knowledge about the real biofilm regulatory network genes, specifically in the case of NCAC species (see Outstanding Questions). Therefore, further studies in this area will contribute towards the identification of new targets to be used to design new nanodrugs against these emerging pathogens.

\section{Outstanding Questions} Are biofilm regulatory genes from NCAC species similar to the known biofilm regulatory genes for $C$. albicans?

What are the signal transduction pathways that regulate biofilm formation in Candida species?

Given the variability of the Candida species genome, what effect does this exert on biofilm formation? 


\section{Acknowledgments}

The authors acknowledge Fundação para a Ciência e Tecnologia (FCT), Portugal, for supporting Sónia Silva (SFRH/BPDT/ 111645/2015). This study was also supported by the Programa Operacional, Fatores de competitividade - COMPETE and by national funds through FCT - Fundação para a Ciência e a Tecnologia under the scope of the projects FCT PTDC/EBBEBI/120495/2010 and RECI/EBB-EBI/0179/2012 (FCOM-01-0124-FEDER-027462).

\section{References}

1. Pfaller, M.a. and Diekema, D.J. (2007) Epidemiology of invasive candidiasis: A persistent public health problem. Clin. Microbiol. Rev. 20, 133-163

2. Berman, J. and Sudbery, P.E. (2002) Candida albicans: a molecular revolution built on lessons from budding yeast. Nat. Rev. Genet. 3, 918-930

3. Douglas, L.J. (2003) Candida biofilms and their role in infection. Trends Microbiol. 11, 30-36

4. Silva, S. et al. (2012) Candida glabrata, Candida parapsilosis and Candida tropicalis: Biology, epidemiology, pathogenicity and antifungal resistance. FEMS Microbiol. Rev. 36, 288-305

5. Silva, S. et al. (2011) Adherence and biofilm formation of nonCandida albicans Candida species. Trends Microbiol. 19, 241-247

6. Mayer, F.L. et al. (2013) Candida albicans pathogenicity mechanisms. Virulence 4, 119-128

7. Silva, S. et al. (2009) Biofilms of non-Candida albicans Candida species: quantification, structure and matrix composition. Med. Mycol. 47, 681-689

8. Desai, J.V. et al. (2014) Fungal biofilms, drug resistance, and recurrent infection. Cold Spring Harb. Perspect. Med. http:// dx.doi.org/10.1101/cshperspect.a019729

9. Nobile, C.J. et al. (2011) A Recently evolved transcriptional network controls biofilm development in Candida albicans. Cell 148, 126-138

10. Finkel, J.S. and Mitchell, A.P. (2011) Genetic control of Candida albicans biofilm development. Nat. Rev. Microbiol. 9, 109-118

11. Al-Fattani, M.A. and Douglas, L.J. (2006) Biofilm matrix of Candida albicans and Candida tropicalis: Chemical composition and role in drug resistance. J. Med. Microbiol. 55, 999-1008

12. Baillie, G.S. and Douglas, L.J. (2000) Matrix polymers of Candida biofilms and their possible role in biofilm resistance to antifungal agents. J. Antimicrob. Chemother. 46, 397-403

13. Chandra, J. et al. (2001) Biofilm formation by the fungal pathogen Candida albicans: development, architecture, and drug resistance. J. Bacteriol. 183, 5385-5394

14. Donlan, R.M. et al. (2002) Biofilms: survival mechanisms of clinically relevant microorganisms. Clin. Microbiol. Rev. 15, 167-193

15. Jain, N. et al. (2007) Biofilm formation by and antifungal susceptibility of Candida isolates from urine. Appl. Environ. Microbiol. 73, 1697-1703

16. Zarnowski, R. et al. (2014) Novel entries in a fungal biofilm matrix encyclopedia. MBio 5, e01333-e01314

17. Fanning, S. et al. (2012) Divergent targets of Candida albicans biofilm regulator Bcr1 in vitro and in vivo. Eukaryot. Cell 11, 896-904

18. Wang, Y.C. et al. (2012) Prediction of phenotype-associated genes via a cellular network approach: A Candida albicans infection case study. PLoS One 7, 1-7

19. Lima-Neto, R.G. et al. (2011) Adherence of Candida albicans and Candida parapsilosis to epithelial cells correlates with fungal cell surface carbohydrates. Mycoses 54, 23-29

20. Nobile, C.J. et al. (2008) Complementary adhesin function in C. albicans biofilm formation. Curr. Biol. 18, 1017-1024

21. Li, F. and Palecek, S.P. (2003) EAP1, a Candida albicans gene involved in binding human epithelial Cells. Eukaryot. Cell 2, 1266-1273

22. Green, C.B. et al. (2005) Construction and real-time RT-PCR validation of Candida albicans PALS-GFP reporter strains and their use in flow cytometry analysis of ALS gene expression in budding and filamenting cells. Microbiology 151, 1051-1060

23. Henriques, M. et al. (2006) Candida species adhesion to ora epithelium: factors involved and experimental methodology used. Crit. Rev. Microbiol. 32, 217-226

24. Li, F. et al. (2007) Eap1p, an adhesin that mediates Candida albicans biofilm formation in vitro and in vivo. Eukaryot. Cell 6 931-939

25. Wan Harun, W.H.A. et al. (2013) Effect of Piper betle and Brucea javanica on the differential expression of hyphal wall protein (HWP1) in non-Candida albicans Candida (NCAC) species. Evid. Based. Complement. Alternat. Med. 2013, 1-6

26. Orsi, C.F. et al. (2014) Impact of Candida albicans hyphal wal protein 1 (HWP1) genotype on biofilm production and funga susceptibility to microglial cells. Microb. Pathog. 69-70C, 20-27

27. Staab, J.F. et al. (1999) Adhesive and mammalian transglutaminase substrate properties of Candida albicans Hwp1. Science 283, 1535-1538

28. Sahni, N. et al. (2009) Genes selectively up-regulated by pheromone in white cells are involved in biofilm formation in Candida albicans. PLoS Pathog. 5, 1-18

29. Pérez, A. et al. (2006) Biofilm formation by Candida albicans mutants for genes coding fungal proteins exhibiting the eightcysteine-containing CFEM domain. FEMS Yeast Res. 6, 1074-1084

30. Panagoda, G.J. et al. (2001) Adhesion of Candida parapsilosis to epithelial and acrylic surfaces correlates with cell surface hydrophobicity. Mycoses 44, 29-35

31. Butler, G. et al. (2009) Evolution of pathogenicity and sexual reproduction in eight Candida genomes. Nature 459, 657-662

32. Castaño, I. et al. (2005) Telomere length control and transcriptiona regulation of subtelomeric adhesins in Candida glabrata. Mol. Microbiol. 55, 1246-1258

33. Cormack, B.P. et al. (1999) An adhesin of the yeast pathogen Candida glabrata mediating adherence to human epithelial cells. Science 285, 578-582

34. Sundstrom, P. (2002) Adhesion in Candida spp. Cell. Microbiol. 4 461-469

35. Filler, S.G. (2006) Candida-host cell receptor-ligand interactions. Curr. Opin. Microbiol. 9, 333-339

36. De Groot, P.W.J. et al. (2008) The cell wall of the human pathogen Candida glabrata: Differential incorporation of novel adhesin-like wall proteins. Eukaryot. Cell 7, 1951-1964

37. Kraneveld, E.A. et al. (2011) Identification and Differential Gene Expression of Adhesin-Like Wall Proteins in Candida glabrata Biofilms. Mycopathologia 172, 415-427

38. Nobile, C.J. and Mitchell, A.P. (2005) Regulation of cell-surface genes and biofilm formation by the $C$. albicans transcription facto Bcr1p. Curr. Biol. 15, 1150-1155

39. Nobile, C.J. et al. (2006) Critical role of Bcr1-dependent adhesins in C. albicans biofilm formation in vitro and in vivo. PLoS Pathog. 2 , 0636-0649

40. Holland, L.M. et al. (2014) Comparative phenotypic analysis of the major fungal pathogens Candida parapsilosis and Candida albicans. PLOS Pathog. 10, 1-18

41. Ding, C. et al. (2011) Conserved and divergent roles of Bcr1 and CFEM proteins in Candida parapsilosis and Candida albicans. PLOS One 6, 1-11

42. Kulkarni, R. et al. (2003) An eight-cysteine-containing CFEM domain unique to a group of fungal membrane proteins. Trends Biochem. Sci. 28, 118-121

43. Connolly, L. et al. (2013) The APSES transcription factor Efg1 is a global regulator that controls morphogenesis and biofilm formation in Candida parapsilosis. Mol. Microbiol. 90, 36-53 
44. Liu, H. (2001) Transcriptional control of dimorphism in Candida albicans. Curr. Opin. Microbiol. 4, 728-735

45. Mancera, E. et al. (2015) Finding a missing gene: EFG1 regulates morphogenesis in Candida tropicalis. G3 5, 849-856

46. Schweizer, A. et al. (2000) The TEAVATTS transcription factor CaTec1p regulates hyphal development and virulence in Candida albicans. Mol. Microbiol. 38, 435-445

47. Bürglin, T.R. (1991) The TEA domain: A novel, highly conserved DNA-binding motif. Cell 66, 11-12

48. Kelly, M.T. et al. (2004) The Candida albicans CaACE2 gene affects morphogenesis, adherence and virulence. Mol. Microbiol. 53, 969-983

49. Kamran, M. et al. (2004) Inactivation of transcription factor gene ACE2 in the fungal pathogen Candida glabrata results in hypervirulence. Eukaryot. Cell 3, 546-552

50. Wächtler, B. et al. (2011) From attachment to damage: Defined genes of Candida albicans mediate adhesion, invasion and damage during interaction with oral epithelial cells. PLoS One 6, 1-14

51. Liu, H. et al. (1994) Suppression of hyphal formation in Candida albicans by mutation of a STE12 homolog. Science 266, 17231726

52. Lane, S. et al. (2001) The basic helix-loop-helix transcription factor Cph2 regulates hyphal development in Candida albicans partly via TEC1. Mol. Cell. Biol. 21, 6418-6428

53. Nett, J. et al. (2007) Putative role of $\beta-1,3$ glucans in Candida albicans biofilm resistance. Antimicrob. Agents Chemother. 51 510-520

54. Nett, J.E. et al. (2010) Role of Fks1p and matrix glucan in Candida albicans biofilm resistance to an echinocandin, pyrimidine, and polyene. Antimicrob. Agents Chemother. 54, 3505-3508

55. Taff, H.T. et al. (2012) A Candida Biofilm-Induced Pathway for Matrix Glucan delivery: implications for drug resistance. PLoS Pathog. 8, 1-13

56. Nobile, C.J. et al. (2009) Biofilm matrix regulation by Candida albicans Zap1. PLoS Biol. 7, 1-15

57. Nett, J.E. et al. (2011) Interface of Candida albicans biofilm matrixassociated drug resistance and cell wall integrity regulation. Eukaryot. Cell 10, 1660-1669

58. González, M.D.M. et al. (1997) Phenotypic characterization of a Candida albicans strain deficient in its major exoglucanase. Microbiology 143, 3023-3032

59. Fonzi, W.A. (1999) PHR1 and PHR2 of Candida albicans encode putative glycosidases required for proper cross-linking of $\beta-1,3-$ and $\beta$-1,6-glucans. J. Bacteriol. 181, 7070-7079

60. Sarthy, A.V. et al. (1997) Phenotype in Candida albicans of a disruption of the BGL2 gene encoding a 1,3- $\beta$-glucosyltransferase. Microbiology 143, 367-376

61. Verma-Gaur, J. et al. (2015) Integration of posttranscriptional gene networks into metabolic adaptation and biofilm maturation in Candida albicans. PLoS Genet. 11, 1-28

62. Pereira, L. et al. (2015) Influence of glucose concentration on the structure and quantity of biofilms formed by Candida parapsilosis. FEMS Yeast Res. http://dx.doi.org/10.1093/femsyr/fov043

63. Alexander, B.D. et al. (2013) Increasing echinocandin resistance in candida glabrata: Clinical failure correlates with presence of FKS mutations and elevated minimum inhibitory concentrations. Clin. Infect. Dis. 56, 1724-1732

64. Garcia-Effron, G. et al. (2009) Effect of Candida glabrata FKS1 and FKS2 mutations on echinocandin sensitivity and kinetics of $1,3-\beta$ D-glucan synthase: Implication for the existing susceptibility breakpoint. Antimicrob. Agents Chemother. 53, 3690-3699

65. Vai, M. et al. (1996) Candida albicans homologue of GGP1/GAS1 gene is functional in Saccharomyces cerevisiae and contains the determinants for glycosylphosphatidylinositol attachment. Yeast 12, 361-368

66. Weig, M. et al. (2001) A GAS-like gene family in the pathogenic fungus Candida glabrata. Microbiology 147, 2007-2019

67. Uppuluri, P. et al. (2010) Dispersion as an important step in the Candida albicans biofilm developmental cycle. PLoS Pathog. $6,1-13$
68. Shen, J. et al. (2008) The Candida albicans pescadillo homolog is required for normal hypha-to-yeast morphogenesis and yeas proliferation. Proc. Natl. Acad. Sci. U.S.A. 105, 20918-20923

69. Uppuluri, P. et al. (2010) The transcriptional regulator Nrg1p controls Candida albicans biofilm formation and dispersion. Eukaryot. Cell 9, 1531-1537

70. Braun, B.R. et al. (2001) NRG1, a repressor of filamentous growth in C. albicans, is down-regulated during filament induction. EMBO J. 20, 4753-4761

71. Murad, A.M. et al. (2001) NRG1 represses yeast hypha morphogenesis and hypha-specific gene expression in Candida albicans. EMBO J. 20, 4742-4752

72. Banerjee, M. et al. (2008) UME6, a novel filament-specific regulator of Candida albicans hyphal extension and virulence. Mol. Biol. Cell 19, 308-317

73. Nobile, C.J. and Mitchell, A.P. (2006) Genetics and genomics of Candida albicans biofilm formation. Cell. Microbiol. 8, 1382-1391

74. Silva-Dias, A. et al. (2014) Anti-biofilm activity of low-molecular weight chitosan hydrogel against Candida species. Med. Microbiol. Immunol. 203, 25-33

75. Kuhn, D.M. et al. (2002) Comparison of biofilms formed by Candida albicans and Candida parapsilosis on bioprosthetic surfaces Society $70,878-888$

76. Ding, C. and Butler, G. (2007) Development of a gene knockout system in Candida parapsilosis reveals a conserved role for BCR 1 in biofilm formation. Eukaryot. Cell 6, 1310-1319

77. Gácser, A. et al. (2007) Targeted gene deletion in Candida parapsilosis demonstrates the role of secreted lipase in virulence. $J$. Clin. Invest. 117, 3049-3058

78. Sheppard, D.C. et al. (2004) Functional and Structural Diversity in the Als Protein Family of Candida albicans. J. Biol. Chem. 279, 30480-30489

79. Murciano, C. et al. (2012) Evaluation of the role of Candida albicans agglutinin-like sequence $(A L S)$ proteins in human oral epithelial cell interactions. PLoS One 7, 1-9

80. Sundstrom, P. et al. (2002) Essential role of the Candida albicans transglutaminase substrate, hyphal wall protein 1, in lethal oroe sophageal candidiasis in immunodeficient mice. J. Infect. Dis. 185, $521-530$

81. Chaffin, W.L. (2008) Candida albicans Cell Wall Proteins. Microbiol. Mol. Biol. Rev. 72, 495-544

82. Sahni, N. et al. (2010) Tec1 mediates the pheromone response of the white phenotype of Candida albicans: insights into the evolution of new signal transduction pathways. PLOS Biol. 8, 1-15

83. Tsuchimori, N. et al. (2000) Reduced virulence of HWP1-deficient mutants of Candida albicans and their interactions with host cells. Infect. Immun. 68, 1997-2002

84. Naglik, J.R. et al. (2006) Candida albicans HWP1 gene expression and host antibody responses in colonization and disease. J. Med. Microbiol. 55, 1323-1327

85. Stoldt, V.R. et al. (1997) Efg1p, an essential regulator of morphogenesis of the human pathogen Candida albicans, is a member of a conserved class of bHLH proteins regulating morphogenetic processes in fungi. EMBO J. 16, 1982-1991

86. Ernst, J.F. (2000) Transcription factors in Candida albicans environmental control of morphogenesis. Microbiology 146, 1763-1774

87. López-Ribot, J. et al. (2002) The filamentation pathway controlled by the Efg 1 regulator protein is required for normal biofilm formation and development in Candida albicans. FEMS Microbiol. Lett 214, 95-100

88. Childers, D.S. and Kadosh, D. (2015) Filament condition-specific response elements control the expression of NRG1 and UME6, key transcriptional regulators of morphology and virulence in Candida albicans. PLoS One 10, 1-15

89. Gulati, M. and Nobile, C.J. (2016) Candida albicans biofilms: development, regulation, and molecular mechanisms. Microbes Infect. 18, 310-321

90. Jacobsen, I.D. et al. (2012) Candida albicans dimorphism as a therapeutic target. Expert Rev. Anti Infect. Ther. 10, 85-93 
91. Du, H. et al. (2012) Roles of Candida albicans Gat2, a GATA-type zinc finger transcription factor, in biofilm formation, filamentous growth and virulence. PLoS One 7, 1-9

92. Robbins, N. et al. (2011) Hsp90 governs dispersion and drug resistance of fungal biofilms. PLoS Pathog. 7, 1-18

93. Pannanusorn, S. et al. (2014) Characterization of biofilm formation and the role of BCR1 in clinical isolates of Candida parapsilosis. Eukaryot. Cell 13, 438-451
94. Singaravelu, K et al. (2014) Genetic determinants of virulence Candida parapsilosis. Rev. Iberoam. Micol. 31, 16-21

95. Riera, M. et al. (2012) New regulators of biofilm development in Candida glabrata. Res. Microbiol. 163, 297-307

96. de Groot, P.W.J. et al. (2013) Adhesins in human fungal pathogens: Glue with plenty of stick. Eukaryot. Cell 12, 470481 